This manuscript is a pre-print and has been submitted for publication in Remote Sensing Applications: Society and Environment.

\title{
Evaluating single and multi-date Landsat classifications of land-cover in a seasonally dry tropical forest
}

${ }^{a}$ Federal University of Campina Grande, Centre for Natural Resources and Technology, Campina Grande, Brazil

${ }^{b}$ Federal University of Campina Grande, Centre for the Sustainable Development of the Semi-Arid, Sumé, Brazil

${ }^{\mathrm{c}}$ University of Exeter, Centre for Water Systems, Exeter, UK

*Corresponding author: andradejmn @gmail.com

ABSTRACT - Accurate information on the land cover is crucial for efficient monitoring and development of environmental studies in the Brazilian Caatinga forest. It is the largest tropical seasonal forest in South America, presenting high biodiversity and is under intense anthropogenic disturbance. Caatinga's land cover is heterogeneous, and rainfall is its primary phenological regulator, presenting mainly deciduous species. Different land-cover patterns show distinct spatial responses to climate and soils changes and modify their physical properties over time. Rainfall is highly variable over time and space, but seasonally concentrated between 2 to 4 months. Therefore, distinguishing the different patterns of land cover through medium spatial-resolution remote sensing, such as the Landsat image series, is challenging, due to the particularities of the climate-vegetation interaction. Two remote sensing approaches have a high potential for efficient land-cover mapping in Caatinga: single and multi-date imagery. The heterogeneity of the land cover of this environment can contribute to a better performance of multispectral approaches, although it is normally applied for singledate images. In a land-cover mapping effort in Caatinga, the temporal factor gains relevance, and the use of time series can bring advantages, but, in general, this approach uses vegetation index, losing multispectral information. This manuscript aims to assess the accuracies and advantages of single-date multispectral and multi-date Normalized Difference Vegetation Index (NDVI) approaches in land-cover classification. Both approaches use the Random Forest method, and the results are evaluated based on samples collected during field surveys. Results indicate that land-cover classification obtained from multi-date NDVI performs better than single-date multispectral data. The lower performance observed for single-date multispectral classification is due to similarities in spectral responses: targets of deciduous vegetation lose their foliage and can be misread as non-vegetated areas. Meanwhile, an accurate classification by time series of plant clusters in seasonal forests allows incorporating seasonal variability of land-cover classes during the rainy and dry seasons, as well as transitions between seasons.

Keywords: Random-Forest; Semi-arid, Caatinga, NDVI, multispectral. 
This manuscript is a pre-print and has been submitted for publication in Remote Sensing Applications: Society and Environment.

\section{Introduction}

The Caatinga is the largest seasonally dry tropical forest in South America (Queiroz et al., 2017), covering an area of about $11 \%$ of the Brazilian territory (Brazil-MMA, 2019). Caatinga's conservation has a direct influence on various environmental processes associated with soil protection, water resources, climate maintenance (Manhães et al., 2016) and economic activities (Brazil-MMA, 2019). The degradation of Caatinga vegetation results from unsustainable exploitation, which, associated with climatic factors, accelerates the desertification process in the region (Drumond, 2004). This ecosystem, of high biodiversity, is under intense anthropogenic disturbance (Ribeiro et al., 2015), and needs accurate information on the land cover for efficient monitoring and development of environmental studies (Gomez et al., 2016).

The Caatinga land cover is heterogeneous, and rainfall is the main phenological regulator of plants in this forest (Moro et al., 2016). The different land-cover patterns are driven by natural and anthropogenic factors, acting on multiple spatial and temporal scales (Moro et al., 2016; Chaves et al., 2008). In these different land-cover patterns, the strategies for adapting to the climate are distinct, resulting in different spatial responses and in the variation of their physical properties over time (Meiado et al., 2012; Vico et al., 2015). The particularities of the climate-vegetation interaction in this forest make it a challenge to distinguish the different landcover patterns through remote sensing (Cunha et al., 2020).

The extraction of land-cover information from remote sensing images is the result of the interaction of the targets on the surface and the electromagnetic radiation in the different spectral bands (Jensen, 2009). The algorithms for distinguishing the different spatial patterns existing in the landscape take advantage of this information to characterize the land cover. The Landsat data structure allows performing temporal analysis in higher spatial resolution (Woodcock et al., 2020), as it provides information on the quality of coverage radiometric, geometric, and identification of clouds and cloud shadows (Wulder et al., 2016; Man et al., 2018), making easier the differentiation of land-cover patterns in high spatial heterogeneity. Although satellites offer practically continuous monitoring, classification of land cover commonly uses multispectral data at a single observation date (Jia et al., 2014; Mahdianpari et al., 2018; Alhassan et al., 2019). However, this approach can induce confusion in the classification of the different existing land-cover patterns in dry seasonal forests, due to the similarity of the vegetation's spectral response in specific phenological stages (Karnieli, 2002). 
This manuscript is a pre-print and has been submitted for publication in Remote Sensing Applications: Society and Environment.

The use of time series can be an alternative for mapping seasonal dry forests, for allowing the monitoring of the different phenological stages of land cover patterns (Hüttich et al., 2011; Gomez et al., 2016). Moreover, the use of vegetation indices allows synthesizing the spectral bands which are most sensitive to biomass variation and photosynthetic activities, simplifying the number of input variables (Tatsumi et al., 2015). However, most studies using vegetation-index time series are carried out in crop areas (Wardlow and Egbert, 2008; Zheng et al., 2015; Mercier et al., 2020), which facilitates the identification of the phenological cover patterns. In seasonal dry forests, the land cover classes and their phenological patterns are not well defined and anthropogenic changes may impair the mapping (Abdi, 2020).

This study assesses two approaches for supervised classification of the Caatinga forest vegetation, one using multi-date Normalized Difference Vegetation Index (NDVI) data and the other using single-date multispectral data. The objectives of this study are: i) to map the Caatinga land-cover classes using these two approaches, comparing both performances for land-cover classes classification, and ii) to assess the impact of the classifications on land-cover mapping once the outcome results provide information for the forest management and conservation. It is also expected that the findings can contribute to enhancing the techniques for mapping seasonally dry tropical forests.

\section{Materials and methods}

\subsection{Study area}

The study area is the Sucuru River basin (Fig. 1), with a territorial area of $1,682.87 \mathrm{~km}^{2}$, located between the geographical coordinates $7^{\circ} 28^{\prime} 30^{\prime \prime}$ and $7^{\circ} 49^{\prime} 30^{\prime \prime}$ South and $36^{\circ} 34^{\prime} 00^{\prime \prime}$ and $37^{\circ} 12^{\prime} 00^{\prime \prime}$ West. In the study area, vegetation degradation has occurred mainly by human activities, such as agriculture and livestock exploitation and wood extraction (Moreira and Targino, 1997; Alves et al., 2017). The climate is hot semi-arid (BSh, Köppen classification), with two distinct seasons: the hot dry season (From June to January) and the very hot rainy season (from February to May), with an average annual rainfall of approximately $520 \mathrm{~mm}$ (Cunha et al., 2020). The soils are shallow and stony, which makes it difficult to retain water after the precipitation events (Moro et al., 2015). The river basin is located in the Cariris Velhos desertification nucleus. This nucleus is one of the areas in the region that presents a high risk of desertification (INSA, 2016). 
This manuscript is a pre-print and has been submitted for publication in Remote Sensing Applications: Society and Environment.
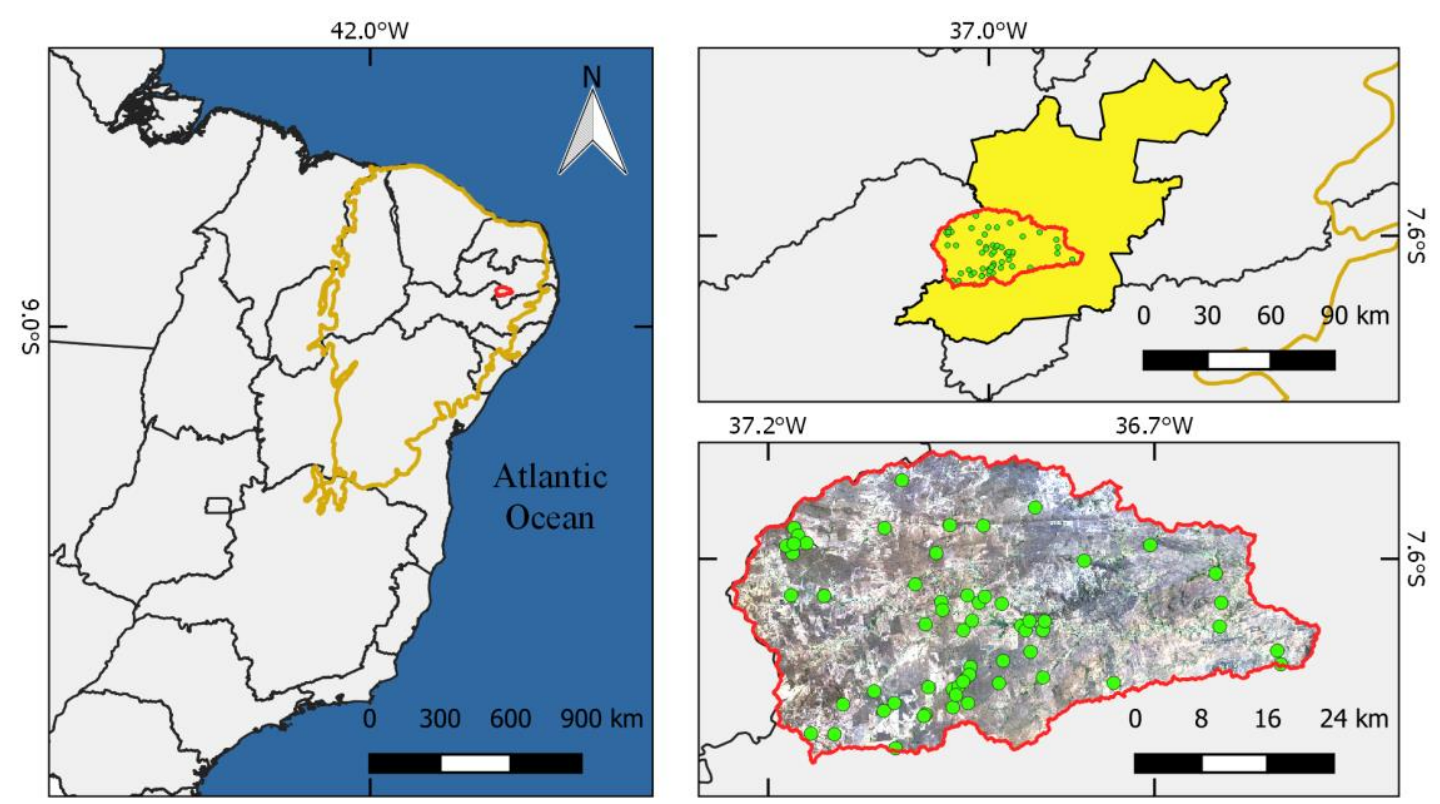

Fig 1: Location of the study area within the Caatinga. The green patterns in the image are the locations of ground-reference data.

\subsection{Methods}

Figure 2 presents the schematic workflow of the methodology applied in this work to evaluate the performance of the classification obtained by single-date multispectral data and the classification by multi-date NDVI data. First, we collected field data and selected satellite images. Then, we reconstructed the smoothed NDVI time series, and identified the temporal patterns of the vegetation cover classes. In the processing step, the Random Forest (RF) method was used for both, single-date multispectral and, multi-date NDVI classification. Finally, it is identified the accuracy and performance of these classifications.

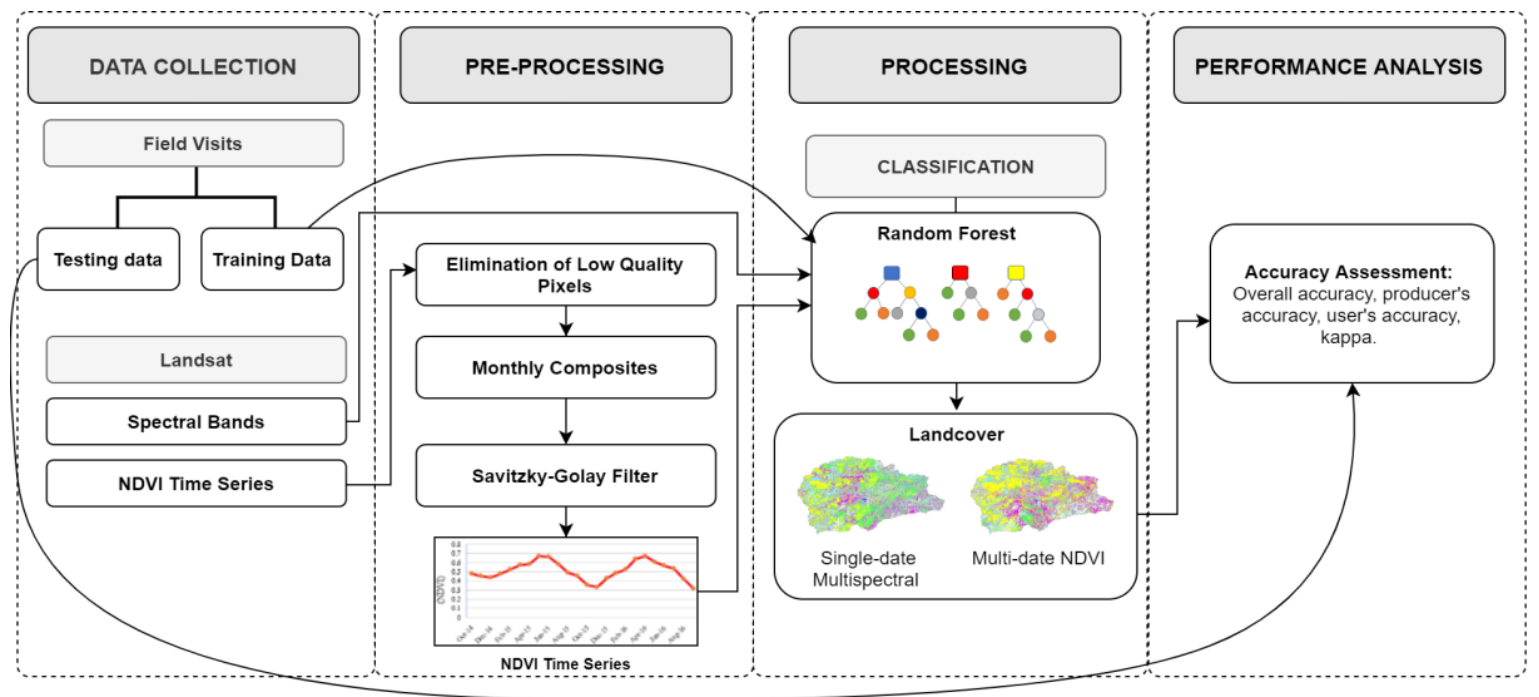


This manuscript is a pre-print and has been submitted for publication in Remote Sensing Applications: Society and Environment.

Fig 2: Schematic workflow of the methodology

\subsubsection{Data collection}

Field surveys collected raw data about Caatinga's land-cover classes in 60 previously chosen land-plots. The surveys occurred in early spring when the deciduous vegetation doesn't lose its leaves yet. In this case, it happened from September 28 to October 7, 2016. The landcover identification survey in the 60 land-plots polygons (Fig. 1) extracted 3,000 pixels randomly, which representing six classes of Caatinga land-cover. The whole set of pixels was randomly grouped into training (2,000 pixels) and validation (1,000 pixels) data sets. Caatinga's land-cover classification followed the methodology proposed by Chaves et al. (2008). Those authors describe and evaluate Caatinga's vegetation in its different stages of anthropization, based on size, morphological features and degrees of coverage. Table 1 shows the used classes according to this methodology. The Bare Soil (BS) class, when there is no vegetation cover, was added, totalling six land-cover classes.

Table 1. Classification of Caatinga's vegetation.

\begin{tabular}{cccc}
\hline Classes & $\begin{array}{c}\text { Predominant Class } \\
\text { Height }(\mathrm{m})\end{array}$ & $\begin{array}{c}\text { Secondary Class } \\
\text { Height }(\mathrm{m})\end{array}$ & Density $(\%)$ \\
\hline VDAS & $>4.5 \mathrm{~m}$ & $3.0-4.5 \mathrm{~m}$ & $>80 \%$ \\
DAS & $>4.5 \mathrm{~m}$ & $3.0-4.5 \mathrm{~m}$ & $>60<80 \%$ \\
OSSB & $3.0-4.5 \mathrm{~m}$ & $1.5-3.0 \mathrm{~m}$ & $>40<60 \%$ \\
OSS & $1.5-3.0 \mathrm{~m}$ & $3.0-4.5 \mathrm{~m}$ & $>40<60 \%$ \\
SSS & $0-1.5 \mathrm{~m}$ & $1.5-3.0 \mathrm{~m}$ & $>20<40 \%$
\end{tabular}

VDAS: Very dense arboreous subarboreous; DAS: Dense arboreous subarboreous; OSSB: Open subarboreous-shrub; OSS: Open shrub-subarboreous; SSS: Sparse Subshrub-shrub. Source: Chaves et al. (2008)

The remote sensing used images are from the Enhanced Thematic Mapper Plus (ETM+) and the Operational Land Imager (OLI) sensors, on board the Landsat 7 and 8 satellites, respectively. These images are freely available by the United States Geological Survey (https://espa.cr.usgs.gov/) and there is 88 Landsat images available from October 2014 to September 2016 that cover the study area (44 from the ETM+ sensor and 44 from the OLI sensor). The combination of images from two sensors results in sampling for the same region 
This manuscript is a pre-print and has been submitted for publication in Remote Sensing Applications: Society and Environment.

at eight-day intervals with thirty meters of spatial resolution. Two different algorithms generate Landsat data at this correction level and depend on the measurement sensor: Landsat 7 ETM+ data are obtained by the LEDAPS software (Masek et al., 2006), and Landsat 8 OLI data are processed by the LaSRC algorithm (Vermote et al., 2016). NDVI is calculated using surface reflectance data from the red and near-infrared (NIR) spectral regions (Tucker, 1979). USGS provides NDVI images with terrain and atmospheric correction, resulting in orthorectified images of high geometric accuracy.

\subsubsection{Pre-processing}

Digital pre-processing of the images, to perform the classification by time series, was done by a R script (R Development Core Team, 2018) developed by the authors, for noise reduction and removal of cloud shadows, clouds, and water pixels. For a smoothed NDVI time serie, the pre-processing uses the Landsat surface reflectance quality assessment (band pixel_qa) which considers only clear pixels (values 66 and 130 for Landsat 7, or 322 and 386 for Landsat 8, USGS, 2019a, b). Holben (1986) showed that the maximum value is a reliable measure to produce representative compositions of the temporal image on a monthly scale. In this study, the NDVI maximum values are used to reduce the original NDVI time series to monthly composite images. The missing values were filled in by linear interpolation. Also, the Savitzky-Golay linear filter is applied (Cao et al., 2018; Savitzky and Golay, 1964), with a fivemonth window to smooth the width, reducing the noise caused by atmospheric variability.

\subsubsection{Classification}

The classification step uses the spectral bands blue, green, red, NIR, short wave infrared 1 (SWIR 1) and short wave infrared 2 (SWIR 2) (Fig. 3) of the image of September 29, 2016, Landsat 8 as input data to the RF method to implement the single-date multispectral approach to classification. In the approach by multi-date NDVI, the NDVI monthly time series from October 2014 to September 2016, totalling 24 composite images (Fig. 3) are the input data to the RF procedure.

Supervised image classification was performed using the Random Forest R package (Liaw and Wiener, 2002). The RF is an ensemble classifier that produces multiple decision trees. The method uses a bootstrap sample of two-thirds of the original training data (in-bag samples) to form trees randomly while the remaining third group of samples known as Out-OfBag (OOB), are used to obtain an internal error estimate (Breiman, 2001; Belgiu and Drãgut, 
This manuscript is a pre-print and has been submitted for publication in Remote Sensing Applications: Society and Environment.

2016; Hüttich et al., 2011). The final classification decision is obtained by the arithmetic mean of the class assignment probabilities calculated by all produced trees, in which each tree votes for a class membership and the final result is the class that obtained the highest number of votes (Belgiu and Drãgut, 2016). This method has been indicated to classify land cover due to its precision (Valbuena et al., 2016). The main parameters of the RF models, defined by the user, are the maximum number of decision trees to be generated in the forest (ntree) and the number of variables used randomly to split each node (mtry) of the tree (Belgiu and Drãgut, 2016; Htitiou et al., 2019). In this study, five hundred decision trees were used and mtry was set to the square root of the number of predictor variables.
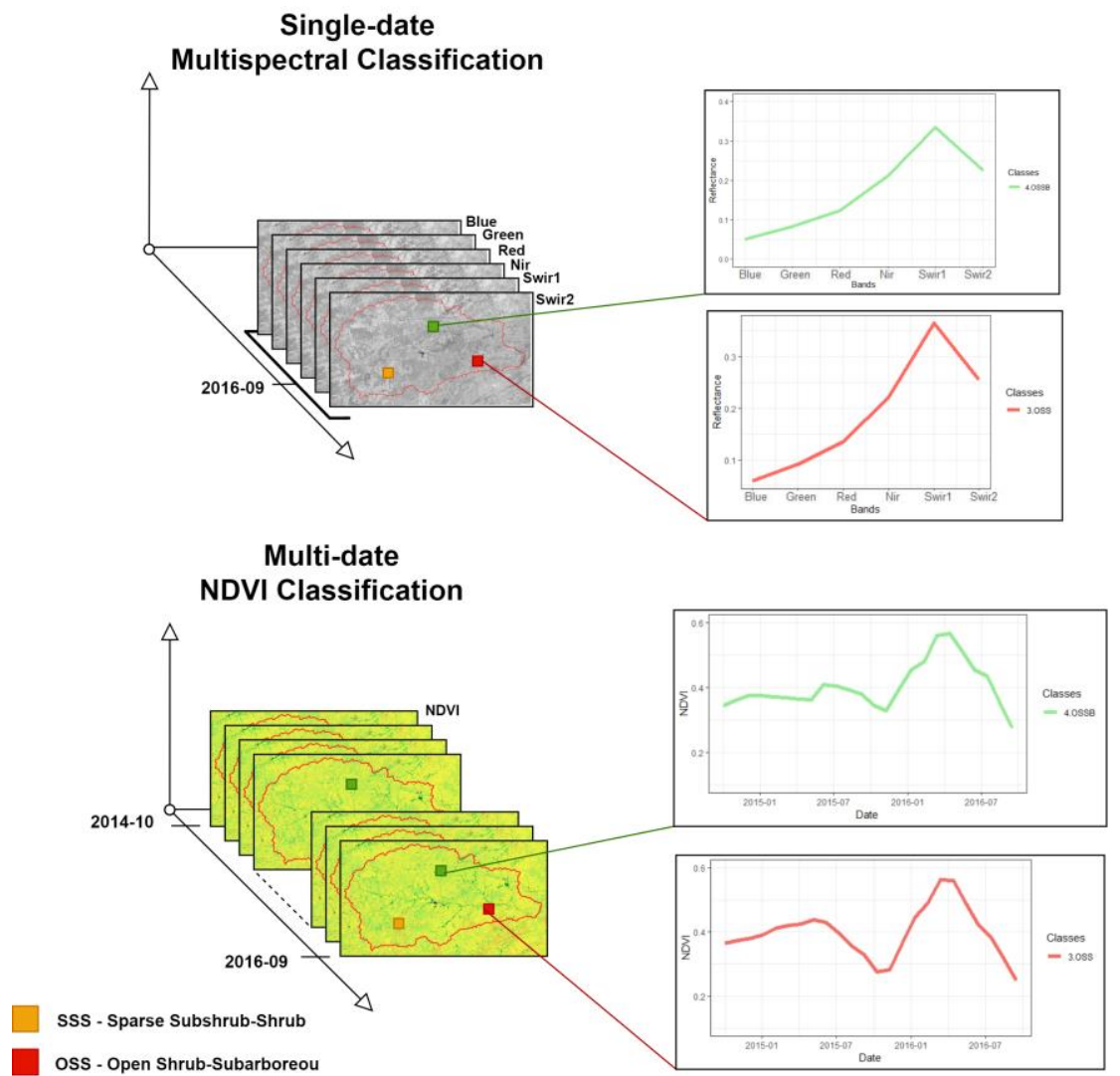

Fig 3: Single-date multispectral and Multi-date NDVI classifications approaches

\subsubsection{Validation and accuracy assessment}

The evaluation of the supervised classifications was carried out based on four performance indicators calculated from the confusion matrix: overall accuracy (OA), Kappa coefficient (k), producer's accuracy (PA), and user's accuracy (UA). The confusion matrix describes the pattern of the allocation class relative to the reference data (Foody, 2002). The 
This manuscript is a pre-print and has been submitted for publication in Remote Sensing Applications: Society and Environment.

Kappa coefficient of agreement $(\mathrm{k})$ uses all the elements of the confusion matrix in its calculation (Eq. 1), constituting an important precision evaluator in images analysis.

$$
k=\frac{n \sum_{i=1}^{m} x_{i i}-\sum_{i=1}^{m} x_{i+} x_{+i}}{n^{2}-\sum_{i=1}^{m} x_{i+} x_{+i}}, \text { Eq. } 1
$$

where $\mathrm{k}$ is an estimate of the kappa coefficient (valuing less than 0 means no agreement; close to 1 means perfect agreement); $x i i$ is the value in row $i$ and column $i$; $x i+$ is the sum of the values in row $i ; x+i$ is the sum of the values in column $i$ of the confusion matrix; $n$ is the total number of samples; and $m$ is the total number of classes (Foody, 2002; Congalton and Green, 2008).

$\mathrm{OA}$ is the division of the total number of correctly classified samples (sum of the elements of the main diagonal of the confusion matrix) by the total number of reference samples. PA is the division of the total number of correctly classified samples in a class by the total number of reference samples for that class, while UA is the division of the total number of samples that were correctly classified in a class by the total number of samples classified in that class (Congalton, 1991). These performance indicators value between $0 \%$ and $100 \%$ (worst and best performance, respectively).

The spectral response of the Caatinga coverage classes concerning the two classification approaches was also analyzed. The classes' boxplots were visually examined to evaluate the separability of each class. This graphic technique illustrates how the training data of the coverage classes are related to the inputs used in the classification approaches.

\section{Results}

The results of the performance assessment showed that the classification based on NDVI monthly time series was more accurate, with an overall accuracy of $88.8 \%$ and a kappa coefficient of 0.86 (Table 3), than the single-date multispectral classification, with an overall accuracy of $81.4 \%$ and a kappa coefficient of 0.78 (Table 2). The comparison of the accuracies for each classification approach, shows that the classifications achieved high accuracies (> 70\%) among the different classes (Fig. 4, Tables 2 and 3). However, the lower accuracies for some classes can be assumed as critical for mapping land-cover, in particular the single-date multispectral classification for the open vegetation (OSSB, OSS, SSS, BS). 
This manuscript is a pre-print and has been submitted for publication in Remote Sensing Applications: Society and Environment.

Table 2: Confusion matrix (\%) for single-date multispectral classification.

\begin{tabular}{lllllllll}
\hline Classified & \multicolumn{7}{c}{ Reference } & \\
\cline { 2 - 6 } & BS & SSS & OSS & OSSB & DAS & VDAS & Total & UA(\%) \\
\hline BS & 73 & 18 & 4 & 0 & 0 & 0 & 95 & 77 \\
SSS & 36 & 139 & 11 & 1 & 0 & 1 & 188 & 74 \\
OSS & 11 & 9 & 122 & 24 & 3 & 0 & 169 & 72 \\
OSSB & 2 & 0 & 23 & 134 & 12 & 7 & 178 & 75 \\
DAS & 0 & 0 & 4 & 1 & 180 & 16 & 201 & 90 \\
VDAS & 0 & 0 & 0 & 3 & 0 & 166 & 169 & 98 \\
Total & 122 & 166 & 164 & 163 & 195 & 190 & 1000 & \\
PA(\%) & 60 & 84 & 74 & 82 & 92 & 87 & OA $(\%)=$ & 81.4 \\
k & 0.78 & & & & & & &
\end{tabular}

UA: user's accuracy; PA: producer's accuracy; OA: overall accuracy; k: kappa. BS: Bare soil. SSS: 224 Sparse Subshrub-shrub. OSS: Open shrub-subarboreous. OSSB: Open subarboreous-shrub DAS: Dense 225 arboreous subarboreous. VDAS: Very dense Arboreous subarboreous.

227 Table 3: Confusion matrix (\%) for multi-date NDVI classification.

\begin{tabular}{lllllllll}
\hline Classified & \multicolumn{7}{c}{ Reference } & \\
\cline { 2 - 6 } & BS & SSS & OSS & OSSB & DAS & VDAS & Total & UA (\%) \\
\hline BS & 94 & 11 & 1 & 1 & 0 & 0 & 107 & 88 \\
SSS & 20 & 153 & 8 & 5 & 1 & 0 & 187 & 82 \\
OSS & 3 & 2 & 144 & 16 & 2 & 1 & 168 & 86 \\
OSSB & 2 & 0 & 11 & 136 & 10 & 2 & 161 & 84 \\
DAS & 3 & 0 & 0 & 3 & 182 & 8 & 196 & 93 \\
VDAS & 0 & 0 & 0 & 2 & 0 & 179 & 181 & 99 \\
Total & 122 & 166 & 164 & 163 & 195 & 190 & 1000 & \\
PA (\%) & 77 & 92 & 88 & 83 & 93 & 94 & OA $(\%)=88.8$ \\
k
\end{tabular}

228 UA: user's accuracy; PA: producer's accuracy; OA: overall accuracy; k: kappa. BS: Bare soil. SSS: 229 Sparse Subshrub-shrub. OSS: Open shrub-subarboreous. OSSB: Open subarboreous-shrub DAS: Dense 230 arboreous subarboreous. VDAS: Very dense Arboreous subarboreous. 
This manuscript is a pre-print and has been submitted for publication in Remote Sensing Applications: Society and Environment.

\section{Producer's accuracy (PA)}

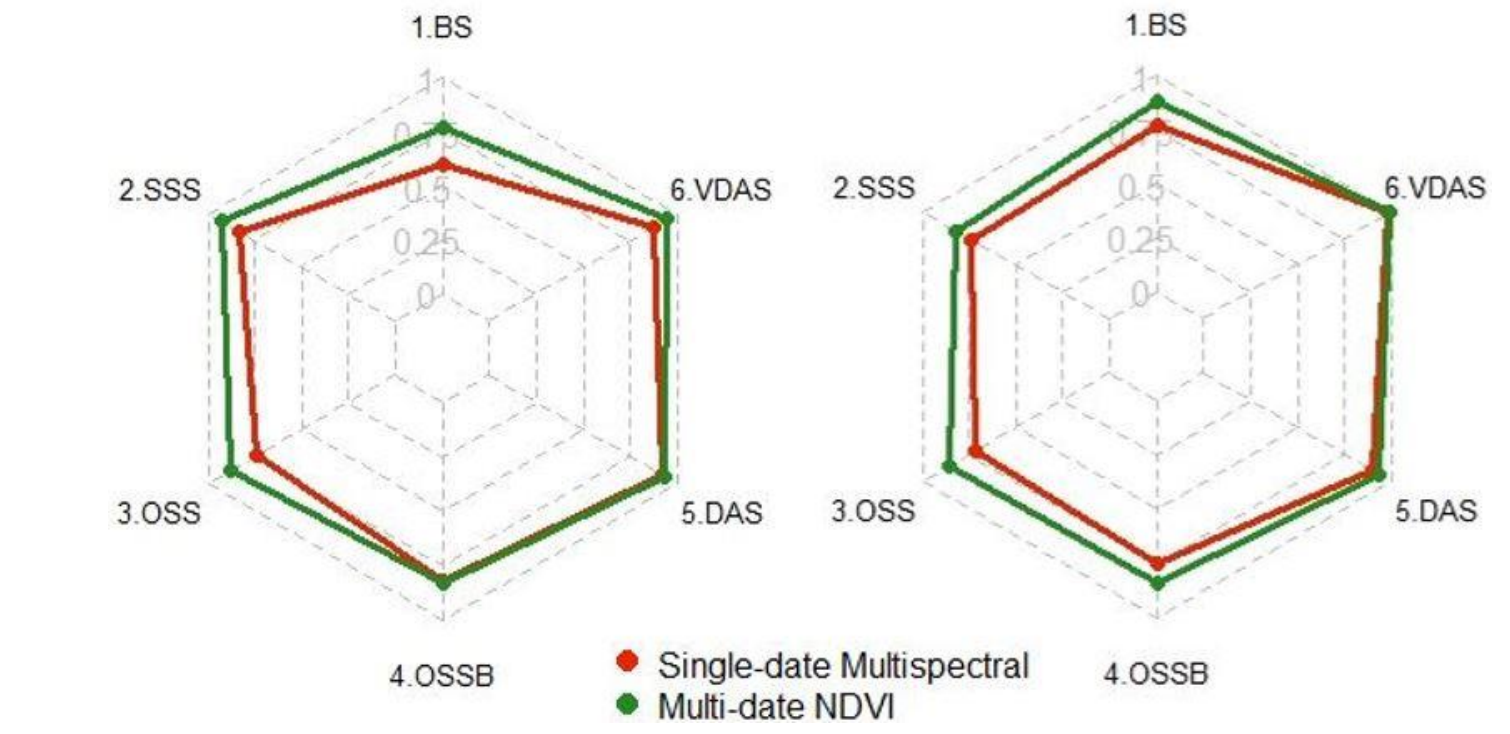

\section{User's accuracy (UA)}

Fig 4: Radar chart representing the user's and producer's accuracies for the single-date multispectral and multi-date NDVI classification

Figure 5 shows the training samples of the six land-cover classes through boxplot graphs for the two approaches and also, that the NDVI monthly time series approach has better revealed distinct patterns for each land cover class than the single-date multispectral approach. In single-date multispectral classification, similar patterns were observed for OSSB, OSS, SSS, BS classes; these classes were precisely those that presented the lowest performance in this classification approach for the user's accuracy (UA) and producer's accuracy (PA). In the accuracy assessment, DAS and VDAS classification showed better performance. VDAS standed out from the others by showing a higher value of NIR. For other classes, SWIR 1 had higher reflectance. The lower variance for spectral bands was observed for DAS class. In the training samples of multi-date NDVI classification, the NDVI lowest values were observed to BE class, however their outlines showed similarities to more vegetated classes; VDAS class presented low phenological variation by multi-date NDVI classification. Results highlights that the worst performance by the multi-date NDVI classification is observed to BE class. 
This manuscript is a pre-print and has been submitted for publication in Remote Sensing Applications: Society and Environment.

249
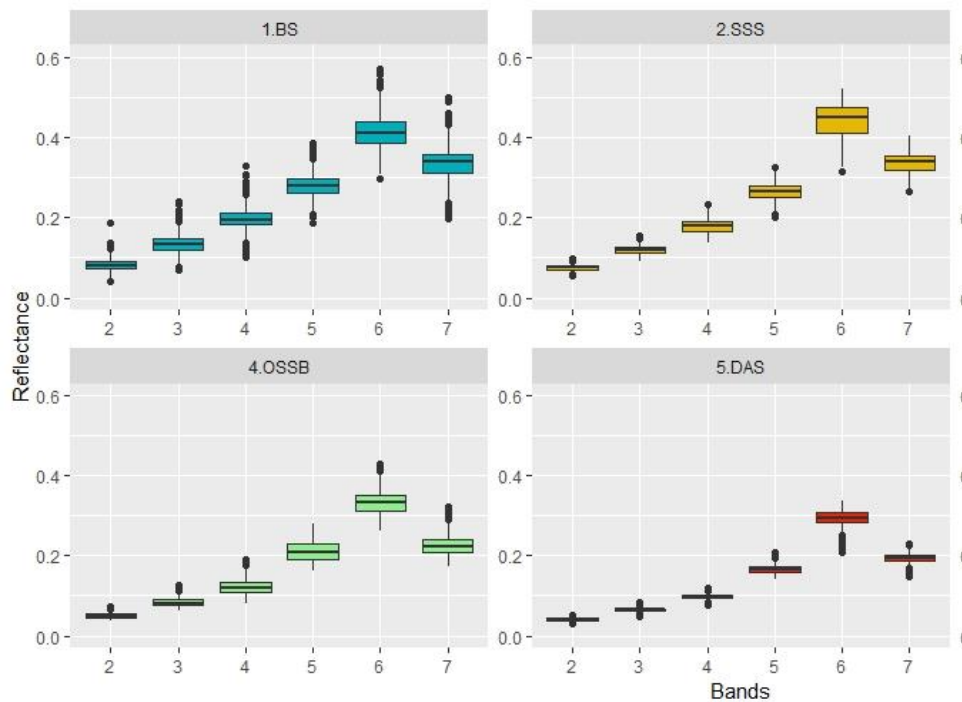

(A)
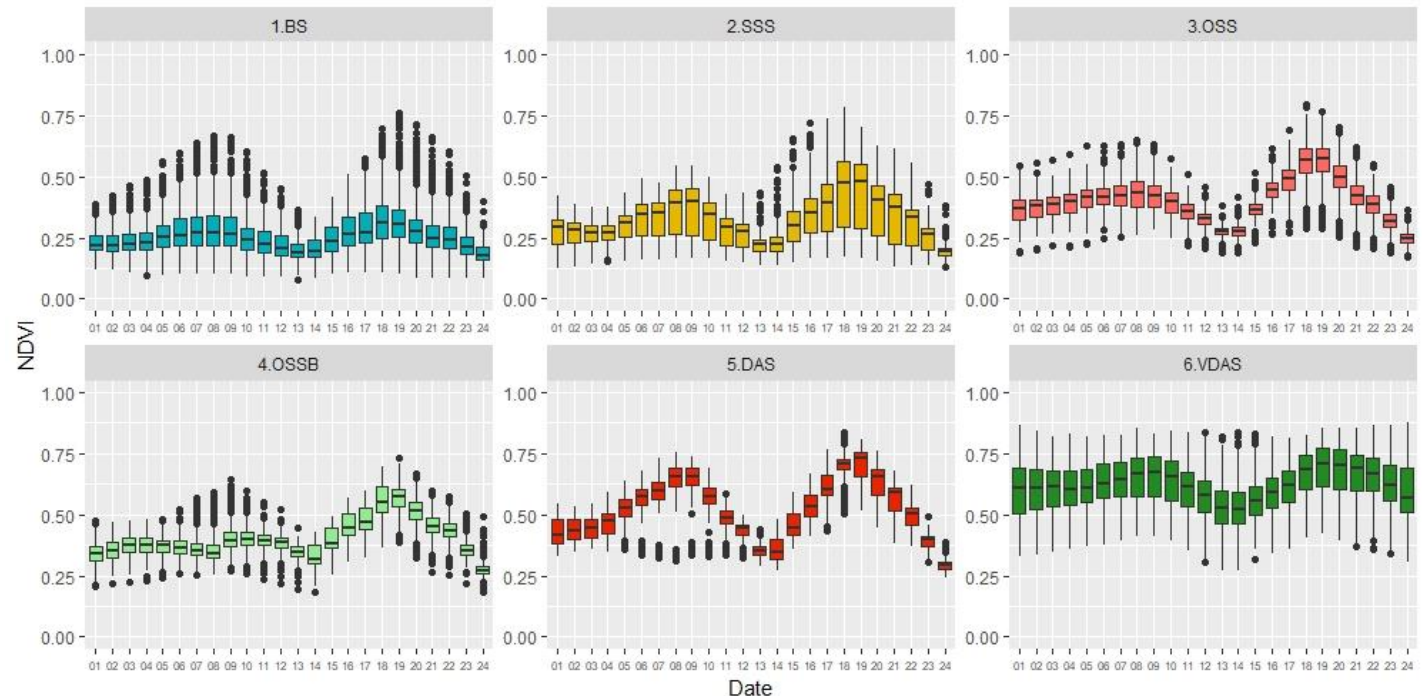

(B)
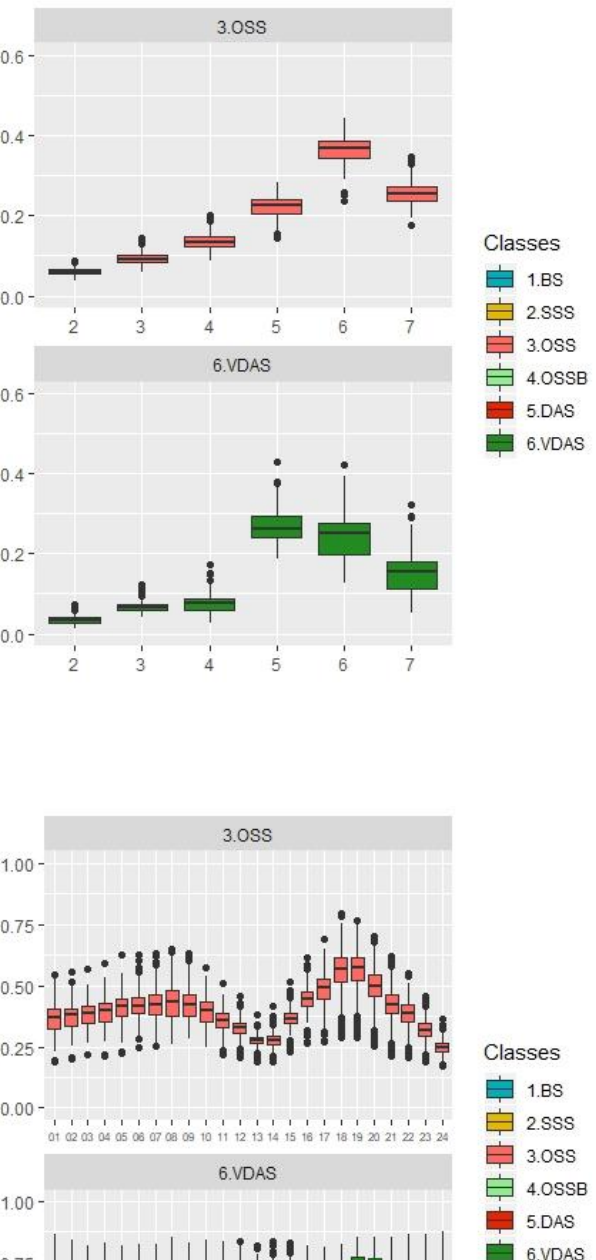

Fig 5: Boxplot graphs of the training samples for land-cover classes A) Spectral bands 2 (blue), 3 (green), 4 (red), 5 (NIR), 6 (SWIR 1), 7 (SWIR 2) of Landsat 8 image of September 29, 2016; B) 24 NDVI Monthly Time series from October 2014 to September 2016.

The values of areas of each land cover class over the studied basin (Fig. 6), classified by the single-date multispectral and multi-date NDVI approaches, show that some classes have different estimates for their areas according to the approach used (Fig. 7). The application of the first approach resulted in the following composition: BS (4.73\%), SSS (20.45\%), OSSB (36.52\%), OSS (22.82\%), DAS (13.36\%), VDAS (2.12\%). The application of the second, however, resulted in: BS (4.96\%), SSS (22.16\%), OSSB (38.63\%), OSS (18.49\%), DAS $(13.25 \%)$, VDAS $(2.51 \%)$. The maps of Fig. 7 show that, although the areas present quite 
This manuscript is a pre-print and has been submitted for publication in Remote Sensing Applications: Society and Environment.

264 similar magnitudes (Fig. 6), there are spatial differences in the land-cover distribution between 265 the maps. In general, the land-cover maps according to the single-date multispectral 266 classification present higher spatial fragmentation of the land-cover classes when compared 267 with the ones generated by multi-date NDVI classification.

268

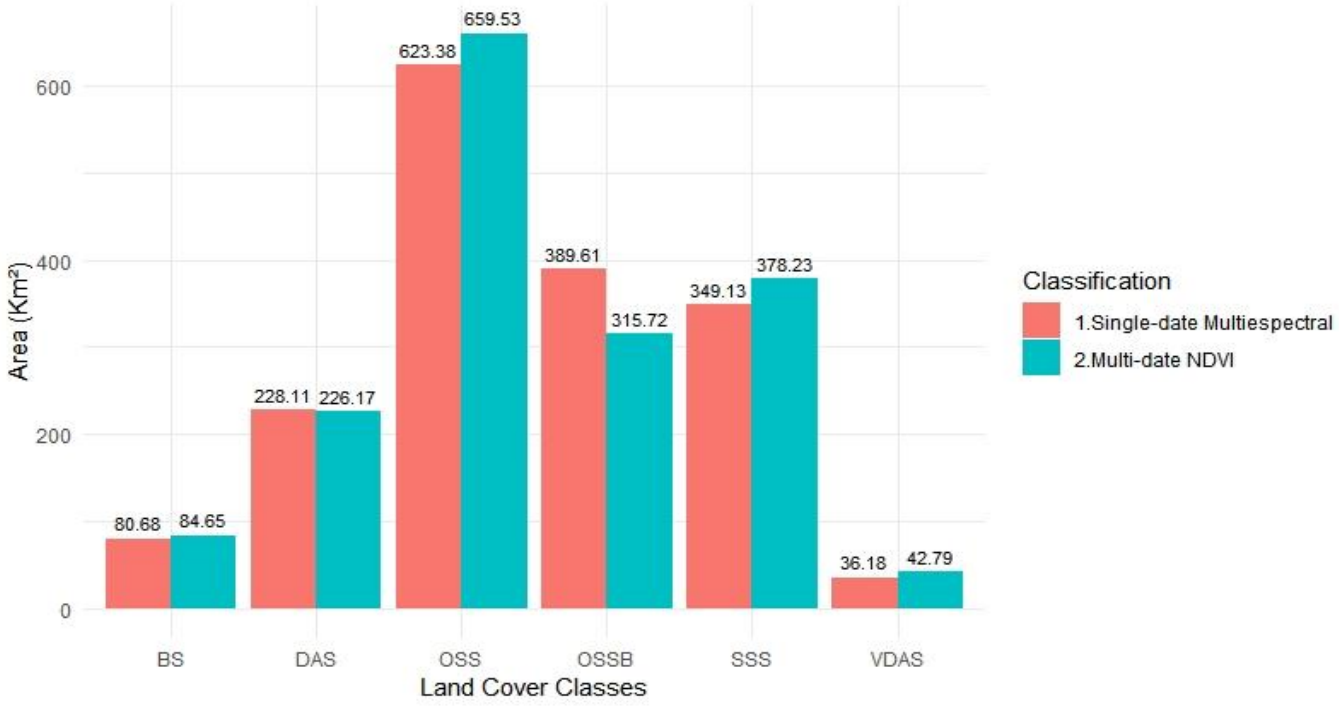

Fig 6: Area $\left(\mathrm{km}^{2}\right)$ derived from the single-date multispectral and multi-date NDVI classifications.

A)

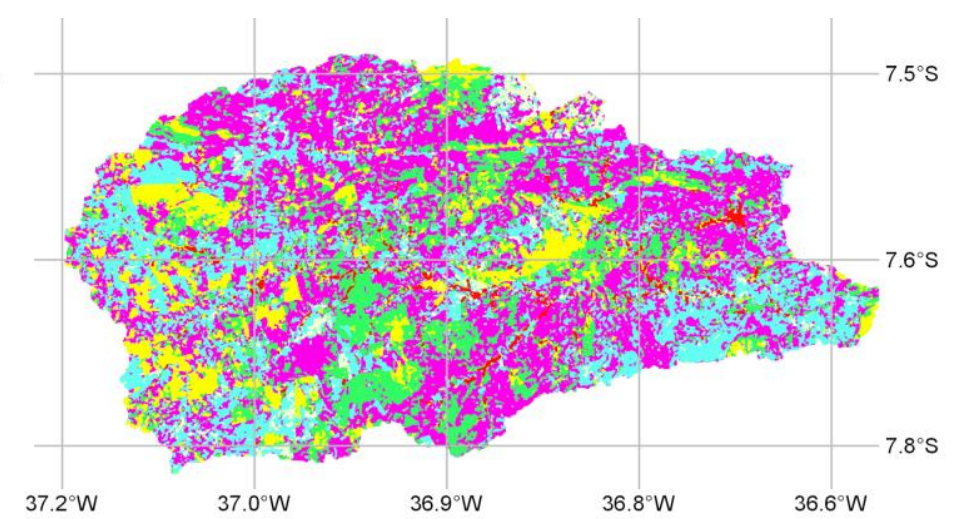

B)

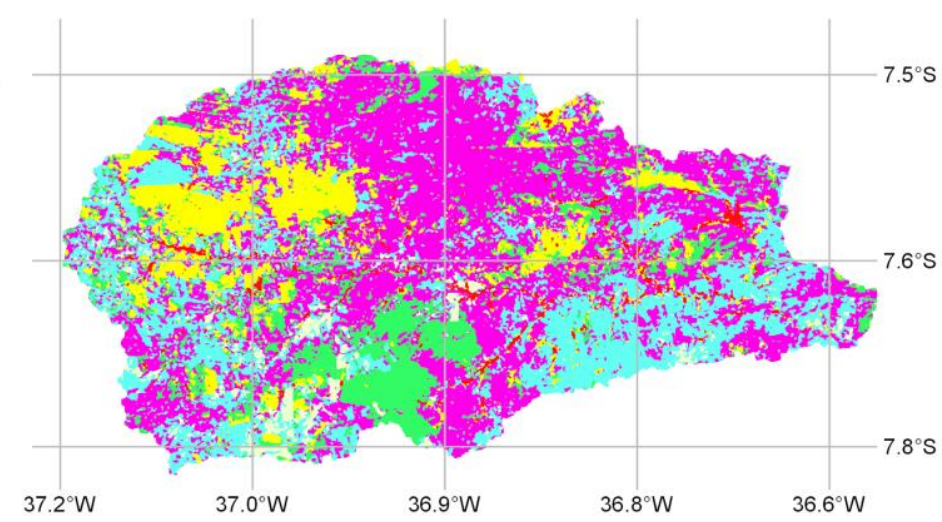

LEGEND Land Cover Classes

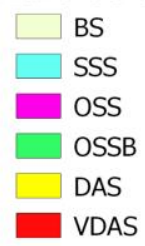

Fig 7: Land-cover maps classified by: A) Single-date multispectral and B) Multi-date NDVI. 
This manuscript is a pre-print and has been submitted for publication in Remote Sensing Applications: Society and Environment.

274

275

276

277

278

279

280

281

282

283

284

285

286

287

288

289

290

291

292

293

294

295

296

297

\section{Discussion}

The lower performance presented by the single-date multispectral classification can be explained by the similarities in the spectral responses of some classes of coverage (Fig. 5.A). SWIR 1 band has the highest reflectance value among the land-cover classes, except VDAS class. This is explained by the contribution of the exposed soil in these cover classes (Ciani et al., 2005; Tian and Philpot, 2015), since most of the Caatinga vegetation is sparse. However, VDAS class has very dense vegetation, reducing the contribution of the exposed soil in its spectral response, being the band NIR its highest reflectance value (Ding et al., 2014). Figure 8 , generated from the average value of reflectance for the training sample, allows visualizing the similarity between classes BS and SSS, and between classes OSS and OSSB. Deciduous vegetation targets lose their foliage during the dry season in the Caatinga environment, and can be confused with non-vegetated areas (Lima et al., 2012). This feature is more significant in the vegetation areas classified as open, since the vegetation in the upper stratum, when losing its leaves, presents large portions of exposed soil. Each of the Caatinga vegetation species responds differently to precipitation and the amount of water storage in soils (Lima and Rodal, 2010; Moro et al., 2015). In the humid period, most open-ground cover areas are invaded by grasses that have low height, confusing the distinction between areas of different vegetation size, due to the elevation of biomass and high momentary photosynthetic activity. Therefore, the near-infrared band will show high reflectivity to the increase in biomass, and the blue and red bands will absorb solar radiation to perform photosynthesis (Kumar et al., 2001). The high heterogeneity of Caatinga land cover makes it harder to distinguish the different land-cover patterns through the interaction between electromagnetic radiation and the surface recorded by sensors onboard the Landsat satellites.

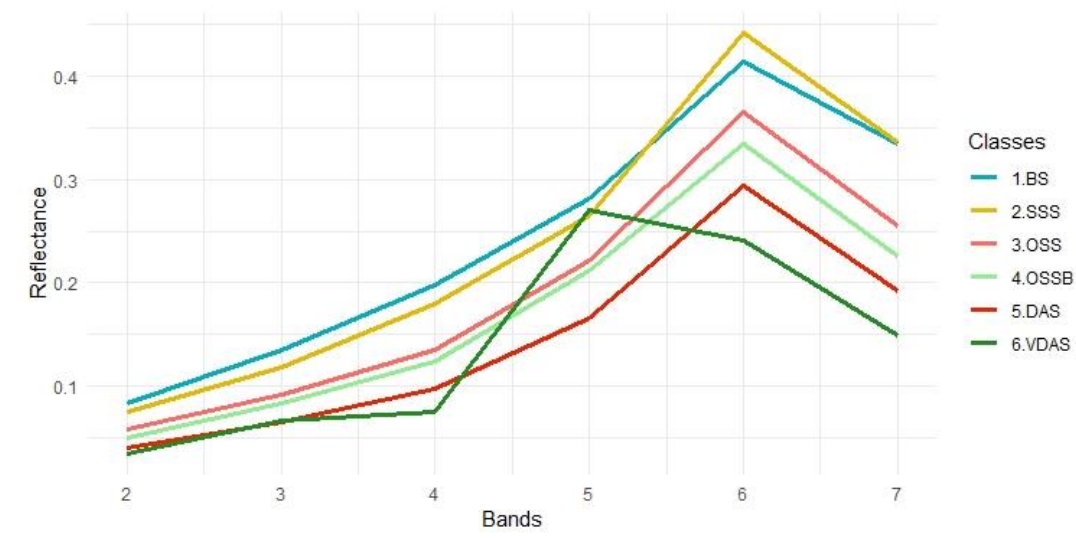

Fig 8: Mean reflectance of the training sample for single-date multispectral classification. 
This manuscript is a pre-print and has been submitted for publication in Remote Sensing Applications: Society and Environment.

300

301

302

303

304

305

306

307

308

309

310

311

312

313

314

315

316

317

318

319

320

321

322

323

324

325

326

327

Our results suggest that the use of vegetation-index time series approach performs better for land-cover classification, compared to single-date multispectral classification in a high heterogeneous environment as the Caatinga. As mentioned by Hüttich et al. (2011) and by Silveira et al. (2018), this approach, as considering the seasonal variability of vegetation activity and phenology cycle in the classification process, increases the overall performance of the land-cover classification in dry seasonal forests. Moreover, the phenology behaviour detected by time series has been pointed out as a key factor to the best performance observed in semi-arid environments (Htitiou et al., 2019). The boxplots in Figure 5.B show that the multidate NDVI classification has revealed different patterns of each coverage classes, which help to ensure good discrimination between classes in the study area. It is possible to identify a time signature of the monitored cover classes, revealing a pattern in the behaviour of each type of land cover (Fig. 9).

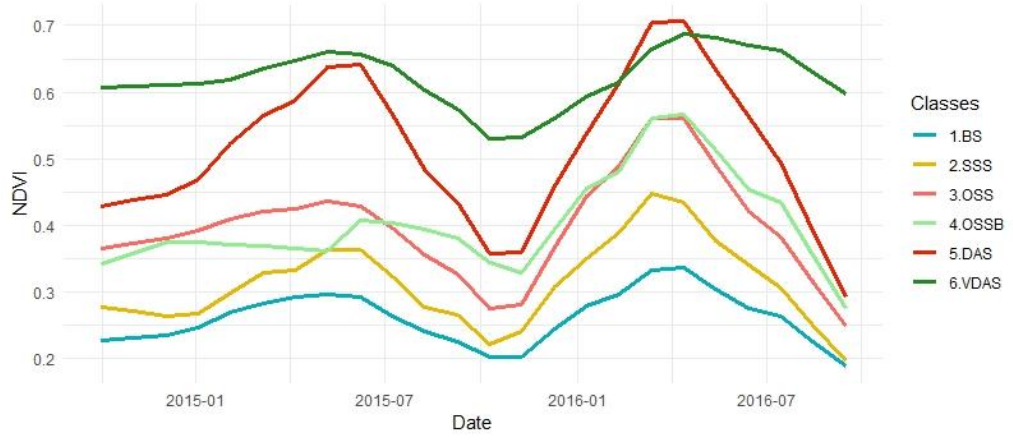

Fig 9: Mean values of NDVI for each class of the training sample from multi-date NDVI classification.

The morphological characteristics of each class can explain the distinction of temporal signatures, mainly those related to vegetation (Arvor et al., 2011). The Caatinga is characterized by significant variation of biomass between the dry and rainy seasons (Barbosa and Kumar, 2016). Therefore, it is necessary to assess the seasonal behaviour of each class (Xia et al., 2017). This will make it possible to distinguish the classes of cover more effectively, as it is possible to verify the response of vegetation throughout the rainy and drought cycles to which the ecosystem is subjected (Levine and Crews, 2019; Gomez et al., 2016).

However, the classes with larger and denser vegetation (VDSA, DSA) showed similar performance in both approaches (Fig. 4), which indicates that the construction of the time series brought low benefit to distinguish these classes, compared with the single-date multispectral approach. VDAS class is characterized by a more stable phenological behaviour (Fig. 9). This 
This manuscript is a pre-print and has been submitted for publication in Remote Sensing Applications: Society and Environment.

328

329

330

331

332

333

334

335

336

337

338

339

340

341

342

343

344

345

346

347

348

349

350

351

352

353

354

355

356

357

358

359

360

can be explained by the proximity of the location of the occurrence of this class to the watercourses, allowing the availability of water throughout the rain and drought cycles. In Figure 5, some classes stand out for the outliers, which can be caused by the difficulty of distinguishing them in the field survey, and also by the anthropic interference in some regions throughout the time series. Anthropogenic activities in Caatinga's land-cover may impair the performance of classification multi-date NDVI (Maldonado et al., 2002; Jianya et al., 2008; Santos et al., 2013). BS class presents outlines with NDVI value from vegetated regions, which suggests that some points may have been used as cropland at certain times (Fig. 5.B). This explains the lowest performance among the classes evaluated by the multi-date NDVI classification. However, when comparing the BS class for both approaches, a lower performance is perceived for the single-date multispectral classification (Fig. 4). The Caatinga vegetation, especially for smaller canopy (SSS and OSS), is scattered with a significant contribution of the soil to the recorded reflectance (Fig. 5.A).

Remarkable differences in the detection of land-cover, such as those observed between the single-date multispectral and multi-date NDVI classifications (Fig. 6 and Fig. 7), can interfere in numerous applications of environmental planning and research in this region, sometimes generating misleading approximations of the reality. In this sense, it is relevant to evaluate the time-series patterns of different land-cover classes in seasonal dry forests and, thus, allow their characterization through satellite images. Continuous ground monitoring of different types of land cover is very important, to face the challenge of land-cover classification in the Caatinga and other dry environments (Zhao et al., 2016).

\section{Conclusions}

The high spatial heterogeneity and temporal variability of the Caatinga vegetation are important elements to consider in the land-cover classification process. The use of a multi-date NDVI approach for the characterization of the land cover in this environment tends to be an effective alternative, compared to the traditional single-date multispectral approach, that takes into account only one instant in time. The lower performance of the single-date multispectral classification was observed in the classes with open vegetation in the upper stratum; for vegetation with higher density, the performance was similar for both approaches. Multi-date NDVI classification presented approximately the same performance for all land-cover classes, except for bare soil. Some training samples of the bare soil class showed vegetation-index 
This manuscript is a pre-print and has been submitted for publication in Remote Sensing Applications: Society and Environment.

361

362

363

364

365

366

367

368

369

370

371

372

373

374

375

376

377

378

379

380

381

382

383

384

385

386

387

388

389

390

391

392

393

values equivalent to dense vegetation, which may have contributed to decreasing the accuracy of the approach. The adoption of this perspective allows for better recognition and depth-in knowledge of the land-cover dynamic in the Caatinga and other similar regions, since it is possible to identify a time signature of each vegetation class over time, enabling a better pattern distinction among the classes..

\section{Acknowledgements}

This work was carried out within the project Mercurius (Estudo de Modelos de Negócios para Federação de Serviços para Suporte a e-Ciência), funded by the Fundação de Amparo à Pesquisa do Estado de São Paulo (FAPESP), under startup grant number \#2015/24461-2. This work forms part of the project NEXUS - SHAE - SF: Segurança Hídrica, Alimentar e Energética na Bacia Estendida do Rio São Francisco, funded by $\mathrm{MCTI} / \mathrm{CNPq} \mathrm{N}^{\circ}$ 19/2017, under startup grant number 441457/2017-7. This work also forms part of the project Impactos das Mudanças Climáticas em Extremos Hidrológicos (Secas e Cheias), funded by CAPES/ANA, under startup grant number 88887.115880/2015-0. During this study, some authors were supported by CNPq/PDE (Grant No 205565/2018-2) and CNPq/PQ (Grant No 313323/2017-8).

\section{References}

Abdi, A. M. (2020). Land cover and land use classification performance of machine learning algorithms in a boreal landscape using Sentinel-2 data. GIScience \& Remote Sensing, 57(1), 1-20. https://doi.org/10.1080/15481603.2019.1650447.

Alhassan, V., Henry, C., Ramanna, S., \& Storie, C. (2019). A deep learning framework for land-use/land-cover mapping and analysis using multispectral satellite imagery. Neural Computing and Applications, 1-16. https://doi.org/10.1007/s00521-019-04349-9.

Alves, T. L. B., de Azevedo, P. V., \& dos Santos, C. A. C. (2017). Influence of climate variability on land degradation (desertification) in the watershed of the upper Paraíba River. Theoretical and Applied Climatology, 127(3-4), 741-751. https://doi.org/10.1007/s00704-0151661-1. 
This manuscript is a pre-print and has been submitted for publication in Remote Sensing Applications: Society and Environment.

394

395

396

397

398

399

400

401

402

403

404

405

406

407

408

409

410

411

412

413

414 Cao, R., Chen, Y., Shen, M., Chen, J., Zhou, J., Wang, C., \& Yang, W. (2018). A simple 415

416

417

418

419

420

421

422

423

424

425

Arvor, D., Jonathan, M., Meirelles, M. S. P., Dubreuil, V., \& Durieux, L. (2011). Classification of MODIS EVI time series for crop mapping in the state of Mato Grosso, Brazil. International $\begin{array}{lllll}\text { Journal of } & \text { Remote } & \text { 32(22), } & \text { 7847-7871. }\end{array}$ https://doi.org/10.1080/01431161.2010.531783.

Barbosa, H. A., \& Kumar, T. L. (2016). Influence of rainfall variability on the vegetation dynamics over Northeastern Brazil. Journal of Arid Environments, 124, 377-387. https://doi.org/10.1016/j.jaridenv.2015.08.015.

Breiman, L. (2001). Random forests. Machine learning, 45(1), 5-32. https://doi.org/10.1023/A:1010933404324.

Belgiu, M., \& Drăguț, L. (2016). Random forest in remote sensing: A review of applications and future directions. ISPRS Journal of Photogrammetry and Remote Sensing, 114, 24-31. https://doi.org/10.1016/j.isprsjprs.2016.01.011.

BRAZIL, Ministério do Meio Ambiente. Caatinga: exclusivamente brasileira. (Agenda Caatinga). http://www.mma.gov.br/biomas/caatinga. Accessed date: 17 March 2019. method to improve the quality of NDVI time-series data by integrating spatiotemporal information with the Savitzky-Golay filter. Remote Sensing of Environment, 217, 244-257. https://doi.org/10.1016/j.rse.2018.08.022.

Ciani, A., Goss, K.-U., \& Schwarzenbach, R. P. (2005). Light penetration in soil and particulate minerals. European Journal of Soil Science, 56(5), 561-574. https://doi.org/10.1111/j.13652389.2005.00688.x.

Chaves, I. D. B., Lopes, V. L., Folliott, P. F., \& Paes-Silva, A. P. (2008). Uma classificação morfo-estrutural para descrição e avaliação da biomassa da vegetação da caatinga. Revista Caatinga, 21(2), 204-213. 
This manuscript is a pre-print and has been submitted for publication in Remote Sensing Applications: Society and Environment.

426 Congalton, R. G. (1991). A review of assessing the accuracy of classifications of remotely 427 sensed data. Remote Sensing of Environment, 37(1), 35-46. https://doi.org/10.1016/00344257(91)90048-b.

429

430 Congalton, R. G., \& Green, K. (2008). Assessing the accuracy of remotely sensed data: principles and practices. CRC press. https://doi.org/10.1201/9781420055139.

432

433 Cunha, J., Nóbrega, R. L., Rufino, I., Erasmi, S., Galvão, C., \& Valente, F. (2020). Surface albedo as a proxy for land-cover clearing in seasonally dry forests: evidence from the Brazilian 435 Caatinga. Remote Sensing of Environment, 238,

111250. https://doi.org/10.1016/j.rse.2019.111250.

437 438 439 440

441

442 443 444 445 446 447 448 449 450 451 452 453 454 455 456 457

Ding, Y., Zhao, K., Zheng, X., \& Jiang, T. (2014). Temporal dynamics of spatial heterogeneity over cropland quantified by time-series NDVI, near infrared and red reflectance of Landsat 8 OLI imagery. International Journal of Applied Earth Observation and Geoinformation, 30, 139-145. https://doi.org/10.1016/j.jag.2014.01.009.

Drumond, M. A., Kiill, L. H. P., Lima, P. C. F., de Oliveira, M. C., de Oliveira, V. R., de Albuquerque, S. G., \& Cavalcanti, J. (2004). Estratégias para o uso sustentável da biodiversidade da caatinga.. In: Silva. J.M.C., Tabarelli, Fonseca, M., M.T., Lins,L.V. Lins (Eds.), Biodiversidade da Caatinga: áreas e ações prioritárias para a conservação, Ministério do Meio ambiente, Brasília , 329-340.

Foody, G. M. (2002). Status of land cover classification accuracy assessment. Remote Sensing of Environment, 80(1), 185-201. https://doi.org/10.1016/S0034-4257(01)00295-4.

Gómez, C., White, J. C., \& Wulder, M. A. (2016). Optical remotely sensed time series data for land cover classification: A review. ISPRS Journal of Photogrammetry and Remote Sensing, 116, 55-72. https://doi.org/10.1016/j.isprsjprs.2016.03.008.

Htitiou, A., Boudhar, A., Lebrini, Y., Hadria, R., Lionboui, H., Elmansouri, L., ... \& Benabdelouahab, T. (2019). The Performance of Random Forest Classification Based on Phenological Metrics Derived from Sentinel-2 and Landsat 8 to Map Crop Cover in an Irrigated 
This manuscript is a pre-print and has been submitted for publication in Remote Sensing Applications: Society and Environment.

458

459

460

461

462

463

464

465

466

467

468

469

470

471

472

473

474

475

476

477

478

479

480

481

482

483

484

485

486

487

Semi-arid Region. Remote Sensing in Earth Systems Sciences, 2(4), 208-224. https://doi.org/10.1007/s41976-019-00023-9.

Holben, B. N. (1986). Characteristics of maximum-value composite images from temporal AVHRR data. International Journal of Remote Sensing, 7(11), 1417-1434. https://doi.org/10.1080/01431168608948945.

Hüttich, C., Herold, M., Wegmann, M., Cord, A., Strohbach, B., Schmullius, C., \& Dech, S. (2011). Assessing effects of temporal compositing and varying observation periods for largearea land-cover mapping in semi-arid ecosystems: Implications for global monitoring. Remote Sensing of Environment, 115(10), 2445-2459. https://doi.org/10.1016/j.rse.2011.05.005.

INSA (2016). Information and Knowledge Management System of the Brazilian Semi-arid Region (SIGSAB, of the acronym in Portuguese). http://sigsab.insa.gov.br. Accessed date: 17 March 2019.

Jensen, J. R. (2009). Remote sensing of the environment: An earth resource perspective 2/e. Pearson Education India.

Jia, K., Wei, X., Gu, X., Yao, Y., Xie, X., \& Li, B. (2014). Land cover classification using Landsat 8 Operational Land Imager data in Beijing, China. Geocarto International, 29(8), 941951. https://doi.org/10.1080/10106049.2014.894586.

Jianya, G., Haigang, S., Guorui, M., \& Qiming, Z. (2008). A review of multi-temporal remote sensing data change detection algorithms. The International Archives of the Photogrammetry, Remote Sensing and Spatial Information Sciences, 37(B7), 757-762.

Karnieli, A., Gabai, A., Ichoku, C., Zaady, E., \& Shachak, M. (2002). Temporal dynamics of soil and vegetation spectral responses in a semi-arid environment. International Journal of Remote Sensing, 23(19), 4073-4087. https://doi.org/10.1080/01431160110116338.

Kumar, L., Schmidt, K.S., Dury, S., Skidmore, A.K. (2001). Review of hyperspectral remote sensing and vegetation science. F. van der Meer (Ed.), Hyperspectral Remote Sensing, Kluwer Academic Press, Dordrecht, 111-155. 
This manuscript is a pre-print and has been submitted for publication in Remote Sensing Applications: Society and Environment.

488

489

490

491

492

493

494

495

496

497

498

499

500

501

502

503

504

505

506

507

508

509

510

511

512

513

514

515

516

517

Levine, D., \& Crews, K. (2019). Time series harmonic regression analysis reveals seasonal vegetation productivity trends in semi-arid savannas. International Journal of Applied Earth Observation and Geoinformation, 80, 94-101. https://doi.org/10.1016/j.jag.2019.04.007.

Liaw, A., \& Wiener, M. (2002). Classification and regression by Random Forest. R news, 2(3), $18-22$.

Lima, A. L. A., \& Rodal, M. J. N. (2010). Phenology and wood density of plants growing in the semi-arid region of northeastern Brazil. Journal of Arid Environments, 74(11), 1363-1373. https://doi.org/10.1016/j.jaridenv.2010.05.009.

Lima, A. L. A., de Sá Barretto Sampaio, E. V., de Castro, C. C., Rodal, M. J. N., Antonino, A. C. D., \& de Melo, A. L. (2012). Do the phenology and functional stem attributes of woody species allow for the identification of functional groups in the semiarid region of Brazil? Trees, 26(5), 1605-1616. https://doi.org/10.1007/s00468-012-0735-2.

Mahdianpari, M., Salehi, B., Rezaee, M., Mohammadimanesh, F., \& Zhang, Y. (2018). Very Deep Convolutional Neural Networks for Complex Land Cover Mapping Using Multispectral Remote Sensing Imagery. Remote Sensing, 10(7), 1119. https://doi.org/10.3390/rs10071119.

Maldonado, F. D., Santos, J. R. D., \& De Carvalho, V. C. (2002). Land use dynamics in the semi-arid region of Brazil (Quixaba, PE): Characterization by principal component analysis (PCA). International Journal of Remote Sensing, 23(23), 5005-5013. https://doi.org/10.1080/0143116021000013313.

Man, C. D., Nguyen, T. T., Bui, H. Q., Lasko, K., \& Nguyen, T. N. T. (2018). Improvement of land-cover classification over frequently cloud-covered areas using Landsat 8 time-series composites and an ensemble of supervised classifiers. International Journal of Remote Sensing, 39(4), 1243-1255. https://doi.org/10.1080/01431161.2017.1399477.

Manhães, A. P., Mazzochini, G. G., Oliveira-Filho, A. T., Ganade, G., \& Carvalho, A. R. (2016). Spatial associations of ecosystem services and biodiversity as a baseline for systematic conservation planning. Diversity and Distributions, 22(9), 932-943. https://doi.org/10.1111/ddi.12459.

Masek, J. G., Vermote, E. F., Saleous, N. E., Wolfe, R., Hall, F. G., Huemmrich, K. F., ... Lim, T.-K. (2006). A Landsat Surface Reflectance Dataset for North America, 1990-2000. IEEE 
This manuscript is a pre-print and has been submitted for publication in Remote Sensing Applications: Society and Environment.

518 Geoscience and Remote Sensing Letters, 3(1), 68-72. https://doi.org/10.1109/lgrs. 5192005.857030.

520 Meiado, M. V., Silva, F. F. S., Barbosa, D. C. A., \& Siqueira Filho, J. A. (2012). Diaspore of 521 the Caatinga: a review. Flora of the Caatingas of the São Francisco River: Natural History and 522 Conservation. Rio de Janeiro: Andrea Jakobsson Estúdio Editorial, 306-365.

523

524

525

526

527 528

529

530

531

532

533

534

535

536

537

538

539

540

541

542

543 Ribeiro, E. M. S., Arroyo-Rodríguez, V., Santos, B. A., Tabarelli, M., \& Leal, I. R. (2015).

544 Chronic anthropogenic disturbance drives the biological impoverishment of the Brazilian

545 Caatinga vegetation. Journal of Applied Ecology, 52(3), 611-620.

546 https://doi.org/10.1111/1365-2664.12420.

Mercier, A., Betbeder, J., Baudry, J., Le Roux, V., Spicher, F., Lacoux, J., Hubert-Moy, L. (2020). Evaluation of Sentinel-1 \& 2 time series for predicting wheat and rapeseed phenological stages. ISPRS Journal of Photogrammetry and Remote Sensing, 163, 231-256. https://doi.org/10.1016/j.isprsjprs.2020.03.009.

Moreira, E.; Targino, I. (1997). Capítulos de geografia agrária da Paraíba. João Pessoa: Editora da UFPB.

Moro, M. F., Silva, I. A., Araújo, F. S. de, Nic Lughadha, E., Meagher, T. R., \& Martins, F. R. (2015). The Role of Edaphic Environment and Climate in Structuring Phylogenetic Pattern in Seasonally Dry Tropical Plant Communities. PLOS ONE, 10(3), e0119166. https://doi.org/10.1371/journal.pone.0119166.

Moro, M. F., Nic Lughadha, E., de Araújo, F. S., \& Martins, F. R. (2016). A Phytogeographical Metaanalysis of the Semiarid Caatinga Domain in Brazil. The Botanical Review, 82(2), 91148. https://doi.org/10.1007/s12229-016-9164-z.

Queiroz, L. P., Cardoso, D., Fernandes, M. F., \& Moro, M. F. (2017). Diversity and evolution of flowering plants of the Caatinga domain. In: Silva J,C; Leal,I; Tabarelli, M.(Eds). Caatinga: the largest tropical dry forest region in South America. Switzerland: Springer International Publishing, 23-63. https://doi.org/10.1007/978-3-319-68339-3_2.

R Development Core Team. (2018). R: A Language and Environment for Statistical Computing. R Foundation for Statistical Computing, Vienna, Austria. https://www.rproject.org. Accessed date: 20 de February 2018. 
This manuscript is a pre-print and has been submitted for publication in Remote Sensing Applications: Society and Environment.

547 Santos, J. M. F. F., Santos, D. M., Lopes, C. G. R., Silva, K. A., Sampaio, E. V. S. B., \& Araújo, 548 E. L. (2013). Natural regeneration of the herbaceous community in a semiarid region in

549 Northeastern Brazil. Environmental Monitoring and Assessment, 185(10), 8287-8302. 550 https://doi.org/10.1007/s10661-013-3173-8.

551 Savitzky, A., \& Golay, M. J. E. (1964). Smoothing and Differentiation of Data by Simplified 552 Least Squares Procedures. Analytical Chemistry, 36(8), 1627-1639. 553 https://doi.org/10.1021/ac60214a047.

554 Silveira, H. L. F., Galvão, L. S., Sanches, I. D., de Sá, I. B., \& Taura, T. A. (2018). Use of 555 MSI/Sentinel-2 and airborne LiDAR data for mapping vegetation and studying the 556 relationships with soil attributes in the Brazilian semi-arid region. International Journal of 557 Applied Earth Observation and Geoinformation, 73, 179-190. 558 https://doi.org/10.1016/j.jag.2018.06.016.

559 Tatsumi, K., Yamashiki, Y., Canales Torres, M. A., \& Taipe, C. L. R. (2015). Crop 560 classification of upland fields using Random forest of time-series Landsat 7 ETM+ data. 561 Computers and Electronics in Agriculture, 115, 171-179. 562 https://doi.org/10.1016/j.compag.2015.05.001.

563 Tian, J., \& Philpot, W. D. (2015). Relationship between surface soil water content, evaporation 564 rate, and water absorption band depths in SWIR reflectance spectra. Remote Sensing of 565 Environment, 169, 280-289. https://doi.org/10.1016/j.rse.2015.08.007.

566 Tucker, C. J. (1979). Red and photographic infrared linear combinations for monitoring 567 vegetation. Remote Sensing of Environment, 8(2), 127-150. https://doi.org/10.1016/0034568 4257(79)90013-0.

569 U.S. Geological Survey, 2019a. Product Guide: LANDSAT 4-7 SURFACE REFLECTANCE 570 (LEDAPS) PRODUCT. Department of the Interior Version. vol. 8. pp. 12. https://prd571 wret.s3.us-west-2.amazonaws.com/assets/palladium/production/atoms/files/LSDS-1370_L4-

572 7_SurfaceReflectance-LEDAPS_ProductGuide-v2.pdf. Accessed date: 03 January 2019.

573 U.S. Geological Survey, 2019b. Product Guide: Landsat 8 Surface Reflectance Code (LaSRC) 574 Product. Department of the Interior Version. vol. 4. pp. 11. https://prd-wret.s3-us-west575 2.amazonaws.com/assets/palladium/production/atoms/files/LSDS-

576 1368_L8_SurfaceReflectanceCode-LASRC_ProductGuide-v2.pdf, Accessed date: 03 January 5772019. 
This manuscript is a pre-print and has been submitted for publication in Remote Sensing Applications: Society and Environment.

578 Valbuena, R., Maltamo, M., \& Packalen, P. (2016). Classification of forest development stages 579 from national low-density lidar datasets: a comparison of machine learning methods. Revista 580 de Teledetección, (45), 15. https://doi.org/10.4995/raet.2016.4029.

581 Vermote, E., Justice, C., Claverie, M., \& Franch, B. (2016). Preliminary analysis of the 582 performance of the Landsat 8/OLI land surface reflectance product. Remote Sensing of 583 Environment, 185, 46-56.https://doi.org/10.1016/j.rse.2016.04.008.

584 Vico, G., Thompson, S. E., Manzoni, S., Molini, A., Albertson, J. D., Almeida-Cortez, J. S., 585 ... Porporato, A. (2015). Climatic, ecophysiological, and phenological controls on plant 586 ecohydrological strategies in seasonally dry ecosystems. Ecohydrology, 8(4), 660-681. 587 https://doi.org/10.1002/eco.1533.

588

Wardlow, B. D., \& Egbert, S. L. (2008). Large-area crop mapping using time-series MODIS 589 $250 \mathrm{~m}$ NDVI data: An assessment for the U.S. Central Great Plains. Remote Sensing of 590 Environment, 112(3), 1096-1116. https://doi.org/10.1016/j.rse.2007.07.019.

591

592 593

594 595 596

597

598

599

600

601

602

603

604

605

606 607
Woodcock, C. E., Loveland, T. R., Herold, M., \& Bauer, M. E. (2020). Transitioning from change detection to monitoring with remote sensing: A paradigm shift. Remote Sensing of Environment, 238, 111558. https://doi.org/10.1016/j.rse.2019.111558.

Wulder, M. A., White, J. C., Loveland, T. R., Woodcock, C. E., Belward, A. S., Cohen, W. B., ... Roy, D. P. (2016). The global Landsat archive: Status, consolidation, and direction. Remote Sensing of Environment, 185, 271-283.https://doi.org/10.1016/j.rse.2015.11.032.

Xia, J., Ning, L., Wang, Q., Chen, J., Wan, L., \& Hong, S. (2017). Vulnerability of and risk to water resources in arid and semi-arid regions of West China under a scenario of climate change. Climatic Change, 144(3), 549-563. https://doi.org/10.1007/s10584-016-1709-y.

Zheng, B., Myint, S. W., Thenkabail, P. S., \& Aggarwal, R. M. (2015). A support vector machine to identify irrigated crop types using time-series Landsat NDVI data. International Journal of Applied Earth Observation and Geoinformation, 34, 103-112. https://doi.org/10.1016/j.jag.2014.07.002.

Zhao, Y., Feng, D., Yu, L., Wang, X., Chen, Y., Bai, Y., ... Gong, P. (2016). Detailed dynamic land cover mapping of Chile: Accuracy improvement by integrating multi-temporal data. Remote Sensing of Environment, 183, 170-185. https://doi.org/10.1016/j.rse.2016.05.016. 